Western University

Scholarship@Western

Department of Economics Research Reports

Economics Working Papers Archive

1994

\title{
Commitment Through Specific Investment in Contractual Relationships
}

Tai-Yeong Chung

Follow this and additional works at: https://ir.lib.uwo.ca/economicsresrpt

Part of the Economics Commons

Citation of this paper:

Chung, Tai-Yeong. "Commitment Through Specific Investment in Contractual Relationships." Department of Economics Research Reports, 9420. London, ON: Department of Economics, University of Western Ontario (1994). 


\author{
RESEARCH REPORT 9420 \\ Commitment Through specific \\ Investment in Contractual \\ Relationships \\ by \\ Ta1-Yeong Chung
}

October 1994

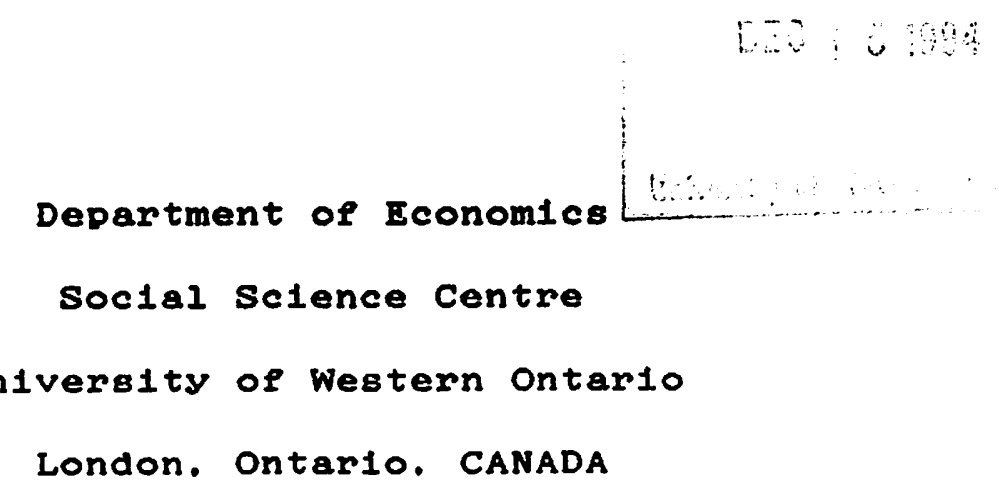

N6A $5 \mathrm{C2}$ 


\title{
Commitment Through Specific Investment In Contractual Relationships
}

\author{
by
}

Tai-Yeong Chung*

Revised, October 1994

* Department of Economics, University of Western Ontario, London, Ontario N6A 5C2, Canada. For useful comments on previous versions, I thank Kyle Bagwell, Avinash Dixit, Aaron Edlin, Michael Hoy, Bentley MacLeod, Michel Poitevin, William Rogerson, Kathy Spier, Seokdong Wang, Ralph Winter, and participants in several seminars. I am especially grateful to Michael Whinston for several helpful suggestions in revising this article. I also gratefully acknowledge financial support from the Social Sciences and Humanities Research Council of Canada (Grant \#410-93-0072). 


\section{Introduction}

Commitment is a fundamental element of strategic environments. The importance of the ability to precommit to threats has been considered in numerous models of incentive theory. Schelling (1960, ch. 2) suggests that a threat which is costly to carry out can be made credible by entering into an advance commitment which makes its fulfillment optimal or even necessary. In a provocative article, Aghion and Bolton (1987) show that the parties to a contract have an incentive to stipulate, in the contract,

a high penalty for breach. Penalties for breach then serve to improve the bargaining power of contracting parties vis-á-vis outsiders and facilitate them to extract rents from outsiders.

Whether such a contractual commitment is effective depends on a number of legal and institutional environments. Masten and Snyder (1989) contend that excessively high liquidated damages are not enforced by the courts, which is called a penalty doctrine. The penalty doctrine thus undermines the contracting parties' ability to commit to ex post inefficient breach behavior. ${ }^{1}$ Masten and Snyder also point out that if the parties to a contract can renegotiate terms of their contract, the commitment power of the original contract is lost. ${ }^{2}$ When such a contractual commitment is ineffective, the parties to a contract may use an alternative instrument to commit themselves against potential competitors.

The purpose of this article is to show that specific investments made by the parties to a contract can be an effective device for committing themselves. In many contractual relationships, the parties make investments that are to some extent relationshipspecific; that is, once made, they have a much higher value inside the relationship than outside. The basic situation considered in this article is one in which a seller makes a contract with a buyer for the performance of a service. Once the contract is made, the seller may make a specific investment that reduces the cost of performance. Consider 
the case in which an opportunity arises that makes it efficient to breach the contract -for instance, the appearance of a new buyer (a third party) with a higher valuation for the seller's performance. The original contracting parties are, in general, unable to capture the entire surplus from the breach; the new buyer will typically be able to enjoy some rents from the new bargain with the seller. ${ }^{3}$

It is shown that when the third party has some negotiation power, the seller has an incentive to make a specific investment that exceeds the socially efficient level in order to extract the third party's rent. Overinvestment on specific assets serves to improve the seller's bargaining position vis-á-vis the third party. This result deserves several comments.

First, the mechanism involved can be described as follows. Recall that specific investments have a much higher value inside the contractual relationship than outside. The more specific investments the breaching party makes, the greater is the switching cost that he must incur when he breaches the original contract. ${ }^{4}$ Because the third party must compensate the breaching party for the switching cost in order to induce a breach, the investment effectively raises her cost of inducing a breach. To extract the third party's rent, thus, the breaching party overinvests in specific assets. The incentive to overinvest is stronger when the third party's negotiation power is greater.

Second, the commitment device used in this mechanism is specific investment, not contractual commitment as in the previous works. A virtue of specific investment as a commitment device is that it is sunk and irreversible, and thus it cannot be renegotiated ex post. An enforcement by the court is not required either. However, contractual commitment (stipulating a penalty for breach) would be effective only if the parties are not able to renegotiate the stipulated damages and only if the courts enforce them.

Third, this result is in sharp contrast to the "underinvestment" result in transactioncost economics literature. 5 The literature shows that an absence (an incompleteness) of a long-term contract between the two parties and the resulting ex post bargaining about 
the terms of trade may create distortions in their relationship. They often invest too little on specific assets because part of the value added generated by their investment is expropriated in the bargaining process. In general, the party who can improve returns in some future trading relationship through investment in specific assets will underinvest because they will have to share the future gain. The overinvestment result of this article, however, is not inconsistent with the general intuition. It can be fit into the intuition in the following way. In the model of this article, the future trading relationship is between contracting parties on one side and the third party on the other side. The contracting parties cannot enter into a long-term contract with the third party simply because the third party is not available at the time of the original contract making. Therefore, they have to bargain about the terms of trade ex post. When the third party has some negotiation power, he will receive parts of the returns from the bargaining. The contracting parties are able to extract rent by overinvesting on specific assets because such investment decreases the total surplus from the bargain. ${ }^{6}$

This article is related to entry deterrence models in industrial organization literature. In particular, Krattenmaker and Salop (1986) show that raising a rival's cost is one way of precommitting to an anti-competitive exclusion. In this article, however, the breaching party (the seller) has an incentive to overinvest in order to precommit himself against a third party (the new buyer) who would be his future trading partner. Therefore, the strategic issue is not one of raising a rival's cost, but of raising the future partner's cost.

This article also is closely related to several works in law and economics literature which examine the efficiency of alternative contract remedies for breach of contract. A party's breach decision depends on the nature of such contract remedies. Similarly, a third party's decision on whether to induce a breach of an existing contract depends on such remedies. Contract remedies influence the ex post bidding behavior by a third party and thus provide different incentives for the ex ante investment decision by the 
breaching party. On the basis of this logic, the welfare properties of current legal remedies can be examined and a new policy on contract remedies can also be proposed.

In fact, Shavell (1980) considers the same basic situation as this article by assuming that the third party does not have any negotiation power (her bid is the same as her valuation). Under this assumption, the new buyer cannot enjoy any rent from the new bargain with the seller. Because there is no rent to extract, there is no need to distort investment for the purpose of commitment. In this article, it is assumed that the third party has some negotiation power, and examine how specific investments are used for commitment.

It is shown that, contrary to Shavell's results, the expectation damage measure that fully compensates a victim of breach is no longer Pareto efficient and it induces the breaching party to overinvest. ${ }^{7}$ It also is shown that the overinvestment result is robust, even when the contracting parties can stipulate damages. In particular, the same overinvestment result is obtained, not only when the court uses the penalty doctrine, but also when stipulated damages can be renegotiated ex post. It is further shown that under-compensatory damages are needed to mitigate the overinvestment problem.

The idea of using specific investments as a commitment device in contractual relationships is not completely new. In a model in which the breached-against party (the original buyer in this article) invests, Chung (1992) investigates whether the investment can be used, in conjunction with stipulated damages, to extract rents from third parties even when the court imposes the penalty doctrine. Because the breachedagainst party's actual loss due to a breach of contract increases with investment, the more specific the investment he makes, the greater the actual loss is. Chung shows that the buyer has an incentive to overinvest in order to relax the constraint imposed by the penalty doctrine. The overinvestment by the breached-against party, which increases the actual loss due to breach, can make excessive stipulated damages be enforceable under the penalty doctrine. 
In the same setup in which only the breached-against party invests, Spier and Whinston (1993) examine whether the possibility of ex post renegotiation completely destroys the role of stipulated damages in inefficiently excluding competitors. Spier and Whinston show that while introducing renegotiation alone destroys the role, introducing both renegotiation and the investment restores it. The overinvestment by the breachedagainst party, which increases the actual loss due to breach, can make excessive stipulated damages be renegotiation-proof.

The current paper in which the breaching party invests differs from both Chung (1992) and Spier and Whinston (1993) in several aspects. ${ }^{8}$ First, those models show that contractual commitment using stipulated damages can be effective when it is supplemented with investment by breached-against party, whereas the current paper emphasizes commitment through specific investment without requiring such a contractual commitment. In those models, given a third party's negotiation power, there exists a (privately) optimal level of stipulated damages. The investment by the breached-against party can be adjusted so that (i) the optimal (excessive) stipulated damages can be enforceable when the court imposes the penalty doctrine, or (ii) the optimal stipulated damages can be renegotiation-proof when ex post renegotiation is possible. In the current paper, however, the breaching party has an incentive to overinvest even without stipulated damages because the investment directly influences the breaching party's switching cost. Since the overinvestment result of the current paper does not require stipulated damages, it is sensitive neither to the adoption of the penalty doctrine nor to the possibility of ex post renegotiation.9

Second, policy implications are different. Recall that, in those models, social inefficiency can be sustained because excessive stipulated damages become effective with the overinvestment by the breached-against party. If the court could fix damages at a different level, investment incentive would be quite different. It is shown in Chung (1992) and Spier and Whinston (1993) that the first-best outcome can be obtained with 
correctly chosen damages -- the efficient expectation damages. ${ }^{10}$ In the present model, however, the efficient expectation damages cannot correct the overinvestment problem because the incentive to overinvest is independent of particular damages. In the present model, under-compensatory damages are needed to mitigate the overinvestment problem.

Third, in those models, the breached-against party can overinvest for a different reason (not for the reason of committing against the third party). Suppose that the court always awards expectation damages so that contractual commitment is no longer available. It is well established that, when the third party does not have any negotiation power, expectation damages induce the breached-against party to overinvest. ${ }^{11}$ When the breached-against party is fully protected by compensatory damages, full returns to investment are guaranteed even when the specific investment is of no use due to the breach. Even if the third party has some negotiation power, the expectation damages induce the same level of overinvestment. In the present model, however, the breaching party overinvests only for the purpose of commitment against the third party.

This article is organized as follows. In Section 2, the model is set up. In Section 3, the model is analyzed, when the contract remedy is expectation damage measure, to show that specific investment (without requiring contractual commitment) can be used as a commitment device against third parties. In particular, it is shown that the breaching-party has an incentive to overinvest on specific assets. In Section 4, the case in which the parties can stipulate damages in the contract is analyzed to show the robustness of this result. It is shown that even if contractual commitment is allowed, the parties do not have incentives to stipulate damages under reasonable conditions. In Section 5, the court's problem of designing optimal damages is considered to mitigate the overinvestment problem. It is shown that the (second-best) optimal damages are under-compensatory. In Section 6, relationships of this article with other literature and its applications are discussed. 


\section{Model}

In the model to be examined, a buyer makes a contract with a seller for the performance of a service (or the delivery of an indivisible good). Once the contract is made, the seller may have to invest in specific assets. ${ }^{12}$ The fundamental uncertainty in the model is the valuation of the seller's performance to a new buyer whose identity is not known initially. The potential new buyer cannot participate in the original contract. After the seller invests, the new buyer learns her valuation of the performance, and may make a bid for the performance. If the new buyer makes a bid, the seller has to decide which buyer to perform for. ${ }^{13}$ The seller has outside opportunities before the original contract is completed.

The case in which the buyer has outside opportunities can be symmetrically analyzed with only changes in notation. For example, a new seller, instead of a new buyer, comes up with a realization of his cost and makes an offer to the buyer. ${ }^{14}$ Therefore, the buyer in this article must be viewed as a promisee or a breached-against party, and the seller must be viewed as a promisor or a breaching party. The new buyer must be viewed as a third party who makes an offer or bid to the promisor so that it may induce a breach of contract.

Let $B$ denote the (incumbent) buyer, $S$ the seller, and $T$ the third party (the new buyer). Assume that all three parties are risk neutral. Let $v$ denote $B$ 's valuation of $S^{\prime} s$ performance. Let $e \in \mathrm{R}_{+}$denote $S^{\prime}$ s investment. The investment is measured in dollars. Given $S^{\prime}$ s investment level $e$, let $c(e)$ denote $S^{\prime}$ s cost of performance for $B$ with $c^{\prime}(e)<0$, $c^{\prime \prime}(e)>0$ ( $S^{\prime}$ s investment reduces the cost of the performance at a decreasing rate). Assume that there are always gains from the trade between $B$ and $S$, that is, $c(0)<v$.

Denote $c(e)$ as $S$ 's cost of performance for $T$, and define $\Delta(e) \equiv c(e)-c(e)$ as the incremental cost of performing for $T$ rather than for $B$. It is essentially a switching cost that $S$ incurs when the buyer is switched from $B$ to $T$. As the switching cost varies with 
$S$ 's investment, it is endogenous in this model. Assume that the switching cost is increasing with the investment, that is, $\Delta^{\prime}(e)>0$. It suggests that $S^{\prime}$ s investment is specific to the contractual relationship between $B$ and $S .{ }^{15}$

$T$ 's valuation of $S$ 's performance is denoted by $\theta$, with its continuous positive density function $f(\theta)$ and the corresponding distribution function $F(\theta)$ over the closed interval $[\theta, \dot{\theta}]$. Assume that $\theta$ is nonverifiable (to the court). ${ }^{16}$ To make the problem interesting, assume that (i) $\theta<v$, and (ii) $v+\Delta\left(e_{e}\right)<\bar{\theta}$, where $e_{e}$ is defined as the unique minimizer of $c(e)+e$. Under this assumption, the support of $\theta$ is large enough so that (i) for some $\theta$, it is efficient for $B$ to obtain the performance, and (ii) for other $\theta$, it is efficient for $T$ to obtain the performance even when the switching cost, $\Delta(\cdot)$, is at its maximum with $e=e_{e} \cdot{ }^{17}$

Only simple contracts are considered in this article. The parties to a contract agree to a price $p$ that is paid from $B$ to $S$ at the time of contracting. Since $\theta$ is nonverifiable by assumption, the contract price cannot be contingent upon it. It is also assumed that $e$ is non-contractible. ${ }^{18}$

Let $x$ denotes the gross damages to be paid from $S$ to $B$ when $B$ does not get the performance (thus, $x$ - $p$ is a net damage payment). ${ }^{19}$ In most cases, a damage payment is not specified in a contract, but it is determined by the court based on a routine damage measure. In other circumstances, parties to a contract may stipulate damages in their contract. In that case, $x$ is a part of the contract. For a clear presentation of the model, it is assumed in this section that $x$ is chosen by the court, and the parties cannot renegotiate ex post. This assumption is relaxed in later sections.

The main result of the present article can be most clearly shown in cases in which the courts award standard compensatory damages, namely, expectation damages (Section 3). Under the damages, the possibility of ex post renegotiation cannot influence parties' investment decision and breach decision. If the courts use other noncompensatory damages, then the parties may want to renegotiate to get around the 
damages. Both cases in which renegotiation is impossible and cases in which it is possible are examined in Section 4, and qualitatively similar results are obtained. Section 5 examines cases in which parties are allowed to stipulate damages in the contract. It is shown that parties to a contract do not have a particular incentive to stipulate damages if ex post renegotiation is possible, or if penalty doctrine is enforced.

The payoffs to the parties depend on the identity of the party who receives the seller's performance and on the realization of the uncertain valuation. Let $p$ denote a contract price, $x$ gross damages, $e$ investment, and $\theta$ a realization of $T$ 's valuation. Let $z$ denote $T$ 's bidding price. The determination of the equilibrium bid price $z$ will be described shortly. Then, when $B$ gets the performance, $B$ 's payoff is $v-p, S^{\prime}$ s payoff is $p$ $c(e)-e$, and $T$ 's payoff is zero. On the other hand, when $T$ gets the performance, $B$ 's payoff is $x-p, S$ 's payoff is $p-x-\tau(e)-e$, and T's payoff is $\theta-z$.

The timing of the model is outlined in Figure 1. At Date $0, B$ and $S$ make a contract $p$ with knowledge of legal rules governing contract damages, namely, value of $x$. After signing the contract, $S$ makes his investment decision on $e$. At Date 1, a valuation to $T$ of the performance, $\theta$, is realized. After observing it, $S$ and $T$ may bargain to determine $T$ 's equilibrium bid $z$, and $S$ must decide which buyer he will serve. It is assumed that the seller cannot perform for both buyers, presumably because of capacity limitations. Finally, at Date 2, the contract is executed, and disputes, if any, are resolved.

\section{< Figure 1 >}

It is assumed that all parties have symmetric information at each stage of the model. The contract terms are public information (that is, these are known to $T$ ). Once realized, $T$ 's valuation, $\theta$, is observable to all three parties. In particular, the switching 
cost, $\Delta(e)$, is assumed to be observable to both parties. ${ }^{20}$ These informational assumptions are made to ensure that ex post bargaining between $S$ and $T$ is efficient.

To complete the model, I have to specify how the equilibrium bid is determined as an outcome of the bargaining between $S$ and $T$. Instead of specifying a particular non-cooperative bargaining process, it is assumed that the bargaining under complete information is efficient, and each party shares the bargaining surplus (a generalized Nash bargaining solution is adopted). ${ }^{21}$ The overinvestment result of this article is quite general because it can be obtained as long as the seller receives a positive share of the bargaining surplus. If parties possessed private information, the bargaining under incomplete information would likely be inefficient. In the conclusion section, I discuss the implication of allowing private information, and conjecture that it would strengthen the overinvestment result.

In a generalized Nash bargaining solution, the price bid by $T$ depends on their negotiation power. Let $\alpha \in[0,1]$ denote $T$ 's negotiation power. At one extreme in which $T$ has no negotiation power, she makes a bid equal to her true valuation, that is, $z=\theta$ for all $\theta .22$ At the other extreme in which $T$ has all the negotiation power, she strategically determines the bidding price as follows. Given a contract price $p$, gross damages $x$, and investment $e, S$ will accept a bid $z$ if $p+z-x-c(e)-e \geq p-c(e)-e$, or equivalently $z \geq x+\Delta(e)$. Hence, if $\theta \geq x+\Delta(e)$, $T$ will make a bid $z=x+\Delta(e)$ at which she will get the performance. Otherwise, $T$ will not make a bid (or will make a bid of zero), and $B$ will get the performance. The equilibrium price bid is defined by

$$
z(\theta, x, e, \alpha)=(1-\alpha) \theta+\alpha(x+\Delta(e))
$$

$T$ will get the performance at $z(\theta, x, e, \alpha)$ if $\theta \geq z(\theta, x, e, \alpha)$, or if $\theta \geq x+\Delta(e)$. Accordingly, the switching of buyer from $B$ to $T$ leads to a breach of the original 
contract between $B$ and $S$. The probability of the event that $T$ gets the performance is defined by

$$
\Phi(x, e) \equiv \operatorname{Prob} .\{\theta \in[\theta, \bar{\theta}]: \theta \geq z(\theta, x, e, \alpha)\}=1-F(x+\Delta(e))
$$

The probability does not depend on the contract term $p$. As it turns out that the investment decision does not depend on $p$ either, the explicit determination of $p$ is not analyzed. ${ }^{23}$

Consider each party's expected payoff. Let $U^{B}, U^{S}$, and $U^{T}$ denote the expected payoff of $B, S$, and $T$ respectively. Let $\Omega \equiv\{\theta \in[\underline{\theta}, \bar{\theta}] \mid \theta \geq x+\Delta(e)\}$, and $\Omega(\underline{\theta}, \dot{\theta}] \backslash \Omega$. Let $\alpha \in[0,1]$ be given. Then

$$
\begin{aligned}
U^{B}(e, x, p) & =\int_{\Omega}[v-p] d F(\theta)+\int_{\Omega}[x-p] d F(\theta) \\
& =v-p+[1-F(x+\Delta(e))][x-v]
\end{aligned}
$$

$$
\begin{aligned}
U S(e, x, p ; \alpha)= & \int_{\Omega}[p-c(e)-e] d F(\theta)+\int_{\Omega}[p+z(\theta, x, e, \alpha)-x-c(e)-e] d F(\theta) \\
& =p-c(e)-e+(1-\alpha) \int_{\Omega}[\theta-(x+\Delta(e))] d F(\theta) \\
U^{T}(e, x, p ; \alpha) & =\int_{\Omega}[\theta-z(\theta, x, e, \alpha)] d F(\theta) \\
& =\alpha \int_{\Omega}[\theta-(x+\Delta(e))] d F(\theta)
\end{aligned}
$$

In (3), the term $[x-v]$ is the gain to $B$ due to the switch from $B$ to $T$, because $v$ is a loss from not getting the performance and $x$ is the gross damages payment that $B$ would receive if he does not get the performance. In (4) and (5), the term $\int_{\Omega}[\theta-(x+\Delta(e))]$ $d F(\theta)$ reflects the expected gains from switching buyers. As it is distributed between $S$ and $T$ according to their negotiation power, $\alpha$ can be interpreted as $T$ 's share of the expected rents from switching buyers. 
Define $U^{B+S} \equiv U^{B}+U^{S}$ as the joint expected payoff function of the contracting parties, and $W \equiv U^{B}+U^{S}+U^{T}$ the social welfare function. Formally,

$$
\begin{aligned}
& U^{B+S}(e, x)= v-c(e)-e+[1-F(x+\Delta(e))][x-v] \\
&+(1-\alpha) \int_{\Omega}[\theta-(x+\Delta(e))] d F(\theta) \\
& W(e, x)=v-c(e)-e+[1-F(x+\Delta(e))][x-v] \\
& \\
&+\int_{\Omega}[\theta-(x+\Delta(e))] d F(\theta)
\end{aligned}
$$

When $\alpha=0, U^{B+S}(e, x)=W(e, x)$ for all $e$ and $x$. In other words, when $T^{\prime}$ 's share of rents is zero, the joint interest of the contracting parties coincides with the social interest. Most analyses of contract remedies have considered this case. As $\alpha$ increases, however, the discrepancy between incentives becomes bigger. Because $U^{B+S}(e, x)$ $W(e, x)=-\alpha \int_{\Omega}[\theta-(x+\Delta(e))] d F(\theta), \alpha$ can also be regarded as a measure of the degree of the externality that the contracting parties impose on $T$.

If $\theta$ and $e$ were verifiable, the social planner would choose a contingent trading rule such that, given investment $e, S$ performs for $T$ if the gain from doing so is greater than or equal to the gain from performing for $B$ (i.e., if $\theta-c(e) \geq v-c(e)$, or equivalently if $\theta \geq v+\Delta(e)$ ), and $S$ performs for $B$ otherwise. The investment decision would be made to maximize the social welfare function given the contingent trading rule. Let $\widetilde{W}$ denote the social welfare function given $e$ and the efficient trading rule. Then,

$$
\widetilde{W}(e)=\int_{\{\theta<\nu+\Delta(e)\}}[v-c(e)] d F(\theta)+\int_{\{\theta \geq v+\Delta(e)\}}[\theta-c(e)] d F(\theta)-e
$$

The efficient investment denoted by $e^{*}$ is defined as a maximizer of $\widetilde{W}(e)$. To ensure that this maximization problem has a unique solution, it is assumed that $\widetilde{W}(e)$ is 
strictly concave. Let $\Phi^{*}$ denote the first-best level of the probability of switching, and let $W^{*}$ denote the first-best level of social welfare function.

Definition 1 . The first-best efficient outcome $\left(e^{*}, \Phi^{*}, W^{*}\right)$ is defined by $e^{*} \equiv \operatorname{argmax}_{\{e\}} \widetilde{W}(e), \Phi^{*} \equiv 1-F\left[v+\Delta\left(e^{*}\right)\right]$, and $W^{*} \equiv \widetilde{W}\left(e^{*}\right)$.

Consider the seller's investment decision, given $p$ and $x$. The seller makes his investment decision without coordinating it with $B$. Given $\alpha \in[0,1]$, the investment schedule $e(x, \alpha)$ is defined as a maximizer of the seller's expected payoff function $U S$. In other words, $e(x, \alpha) \equiv \operatorname{argmax}_{\{e\}} U S(e, x, p ; \alpha)$.

\section{Analysis}

To show that specific investment can be used as a commitment device, the model is analyzed in this section under the assumption that contract remedy is the one provided by the court. Therefore, contractual commitment in which stipulated damages designed by parties play a role is prohibited in this section.

Specifically, it is assumed that contract damages are determined by the most popularly used rule of assessing damages -- expectation damage measure (the ED rule, hereafter). The ED rule intends to protect $B$ 's expectation interest, which is his interest in having the benefit of the bargain by being put in as good a position as he would have been in if the contract had been performed. The expectation damages are also called compensatory damages because the victim of the breach is fully compensated with the damages. ${ }^{24}$

In the notation of this article, the amount of actual damages to be awarded under the ED rule is $v$. Outcomes induced under the ED rule can be calculated by substituting $v$ for $x$ in the specification of the model. It is well established in the literature that the 
ED rule induces ex post efficient trading decisions. Since the ex post decision are efficient, allowing ex post renegotiation does not change any result. Under the ED rule, it can be shown that $W(e, v)=\widetilde{W}(e)$. Thus, $e^{*}$ maximizes not only $\widetilde{W}(e)$, but also $W(e, v)$.

\section{A special case in which the third party has no negotiation power}

Before analyzing the model, consider a special case in which the third party has no negotiation power for contrast. When $T$ has no negotiation power, $T$ makes a bid equal to her true valuation. This situation would be relevant if there were many third parties competitively bidding against each other for the seller's contractual service.

It is well established that the ED rule induces ex post efficient decisions. The breaching party internalizes any external cost imposed on the potential victim of breach. If parties to a contract do not make specific investment, the ED rule implements the first-best outcomes. Shavell (1980) also shows that when the breaching party is the only investing party, the ED rule induces both efficient breach and efficient investment decisions, provided that $T$ has no negotiation power. Efficient investment is obtained because (i) the ED rule induces ex post efficient breach decisions, (ii) the investing party, $S$, does not share its future return with the third party, and thus (iii) $S$ receives correct returns from his investment regardless of whether he serves for $B$ or $T$. This is summarized as:

Proposition 1. Assume that $T$ has no negotiation power. The ED rule can implement the first-best outcome.

Proof. Substituting $\alpha=0$, and $x=v$ (the ED rule) into equations (4) and (7), and comparing them gives us $U^{S}(e, v)=W(e, v)-(v-p)$. Because $e^{*}$ maximizes $W(e, v)$, the seller's optimal choice also is $e^{*}$. Given that the seller invests efficiently, the ED rule induces efficient breach decisions. Q.E.D.25 
Incentive for Overinvestment under the ED rule

Now consider the case in which $T$ has some negotiation power (that is, $\alpha \in(0,1])$. In this subsection, the seller's incentive to overinvest is investigated under the ED rule to show the commitment role of specific investment. Recall that, under the ED rule, $x=v$. To examine the seller's investment incentives, compare the seller's expected payoff function in (4) with the social welfare function in (7). Under the ED rule, we have

$$
U^{S}(e, v, p ; \alpha)=W(e, v)+(p-v)-\alpha \int_{\Omega}[\theta-(x+\Delta(e))] d F(\theta)
$$

The last term in (9) indicates a source of overinvestment. When the seller make investment decision, he ignores its potential effects on the third party's payoff. In (9), the $\operatorname{term} \int_{\Omega}[\theta-(x+\Delta(e))]$ is the expected gains from switching buyers. The third party gets its share $\alpha$ of the expected gains. Since the investing party ignores this, he has an incentive to reduce the total amount of the expected gains by overinvesting on specific assets.

Proposition 2. Assume that $T$ has some negotiation power. The ED rule cannot implement the first-best outcome. In particular, the ED rule induces over-investment by the breaching party $S$.

Proof. From (9), we obtain

$$
U_{e}^{S}(e, v)=W_{e}(e, v)+\alpha[1-F(v+\Delta(e))] \Delta^{\prime}(e) \text {. }
$$

Therefore,

$$
\begin{aligned}
\left.U_{e}^{S}(e, v)\right|_{e=e^{*}} & =W_{e}\left(e^{*}, v\right)+\alpha\left[1-F\left(v+\Delta\left(e^{*}\right)\right)\right] \Delta^{\prime}\left(e^{*}\right) \\
& =\alpha\left[1-F\left(v+\Delta\left(e^{*}\right)\right)\right] \Delta^{\prime}\left(e^{*}\right)>0
\end{aligned}
$$


from $\Delta^{\prime}(e)>0$ and $\left[1-F\left(v+\Delta\left(e^{*}\right)\right)\right]>0$. This shows that, under the ED rule, the seller has an incentive to invest at the level that exceeds the first-best investment. Q.E.D.

Overinvestment on specific assets generates an external cost to $T$ that is not considered by the investing party $S$. The overinvestment makes it difficult for $T$ to induce a breach of the contract ( $T$ must raise the bid price), because the equilibrium bidding price $z$ is increasing in $S$ 's investment $e$ in (1). In other words, by making a large amount of specific investment that raises the switching cost, $S$ can commit to a better position in the future bargaining with a third party. The incentive to overinvest becomes stronger when the third party's negotiation power is greater..$^{26}$

This result is in sharp contrast to Proposition 1 in which the ED rule induces efficient investment when $T$ has no negotiation power. When $T$ does not enjoy any rents, there is no incentive to use overinvestment as a precommitment device. Proposition 2 also is different from the well-known result that the ED rule induces overinvestment by the breached-against party. Under the ED rule, the breached-against party is completely insured for the benefit that he expects to receive from the contract, and thus he overinvests. Proposition 2 shows that investment by the breaching party can be used strategically as a commitment device.

\section{Stipulated Damages}

In the previous section, it is shown that specific investment alone can be an effective commitment device without requiring any contractual commitment. In this section, contractual commitment is allowed by assuming that parties to a contract can stipulate damages in the contract. It is shown that the possibility of using stipulated 
damages has no additional commitment effects. In particular, provided that the default contract remedy is awarding compensatory damages, the parties to a contract do not have an incentive to stipulate any other damages if the penalty doctrine is adopted or if ex post renegotiation is possible.

Assume that parties to a contract can stipulate damages in their contract. That is, $x$ is chosen by the parties to a contract at the time of contracting in this section. The case in which the parties can commit to the stipulated damages (no renegotiation) and in which the court imposes the penalty doctrine is first considered. The case in which the parties cannot commit not to renegotiate the stipulated damages is studied next. It is shown that the equilibrium outcome in each of these two cases is exactly the same as the one under the ED rule. Therefore, the overinvestment result shown in the previous section (See Proposition 2) is robust to the introduction of contractual commitment.

\section{No renegotiation of stipulated damages and penalty doctrine}

Assume that the parties to a contract can commit to stipulated damages (no renegotiation) and the court imposes the penalty doctrine, that is, the court does not enforce stipulated damages that exceed compensatory damages. Consider first what level of damages the contracting parties want to stipulate if they believe that any stipulated damages are enforceable. Let $x^{F}$ denote such damages that the parties stipulate to maximize their joint payoff, $U^{B+S}$.

It is shown that the privately optimal stipulated damages exceed compensatory damages, that is, $x^{F}>v .{ }^{27}$ By committing, in the initial contract, to high stipulated damages, the parties to the contract can raise the price that a third party has to pay to induce a breach of contract. This implies that if any stipulated damages are enforced, $S$ has a stronger incentive to overinvest than he has under the ED rule, because $S^{\prime}$ 's optimal investment is increasing in $x$ (see Lemma 1 in the Appendix). 
Next consider the role of the penalty doctrine. Because the court will not enforce stipulated damages that exceed compensatory damages, $x^{F}(>v)$ cannot be enforced and actual damages awarded will be the same as the compensatory damages, and thus the same as expectation damages. Under the penalty doctrine, therefore, the breaching party has the same incentive to overinvest as he has under the ED rule.

Proposition 3. Assume that $T$ has some negotiation power, and that parties to a contract can commit to stipulated damages. If the court uses penalty doctrine, the damages actually awarded will be the same as expectation damages. The equilibrium outcome under the penalty doctrine is the same as the one under the ED rule. Under the penalty doctrine, thus, the breaching party has an incentive to overinvest.

Proof. See the Appendix B.

\section{Renegotiation of stipulated damages 28}

Consider the case in which the contracting parties can renegotiate stipulated damages after observing the third party's valuation. ${ }^{29}$ Since the contracting parties can renegotiate under complete information, the breach decisions will be ex post efficient. Regardless of the level of stipulated damages, $T$ will get the seller's performance if $\theta>$ $v+\Delta(e)$. Realizing the possibility of renegotiation, the third party will make a bid as if the effective damages are $v$. From (1), the equilibrium price bid becomes

$$
z\left(\theta, x^{S}, e, \alpha\right)=(1-\alpha) \theta+\alpha(v+\Delta(e))
$$

With renegotiation, stipulated damages, $x$, have no effect on the third party's bidding behavior, although the damages can influence $S$ 's investment decision. The contracting parties will choose stipulated damages in order to induce $S$ to invest at the level that maximizes their joint interests. It turns out that the optimal stipulated 
damages are the same as expectation damages, $v$. If stipulated damages were noncompensatory, there would be ex post renegotiation in which a sharing of bargaining surplus occurs. It would distort the investment incentives. With the optimal stipulated damages, there is no renegotiation because the expectation damages induce efficient breach decisions. ${ }^{30}$ Thus, the previous result of this article on the ED rule applies to this case.

Proposition 4. Assume that $T$ has some negotiation power. When the contracting parties can stipulate damages and are able to renegotiate ex post, the optimal stipulated damages are at the same level as expectation damages. Therefore, the equilibrium outcome under the stipulated damages and renegotiation is exactly the same as the one under the ED rule. In particular, the breaching party has the same incentive to overinvest.

Proof. See the Appendix B.

Proposition 3 and Proposition 4 show that once specific investment is available as a commitment device, there is no particular need to use stipulated damages. This also is consistent with the observation that most of contracts do not include stipulated damages.

\section{Design of Optimal Damages}

It is shown in Section 3 that when the court uses a standard compensatory damages, the breaching party overinvests to commit against third parties. It is shown in Section 4 that the overinvestment result persists even when stipulated damages are allowed. In this section, the issue of designing optimal damages by the court is examined to mitigate the incentive for overinvestment. 
The attention is restricted to constant damages chosen by the court in order to compare them with compensatory damages. Let the SC rule refer to the rule that the court awards socially chosen constant damages for breach of contract. Let $x^{S}$ denote the constant damages that the court would choose to maximize the social welfare function, given that the seller makes his investment decision with knowledge of the damages. It is called the SC damages. The SC damages will generally be different from the expectation damages. In that case, ex post decisions will not be efficient unless renegotiation among the parties is feasible. Both the case in which renegotiation is not possible and the case in which it is possible are examined. It is shown that the SC damages are under-compensatory regardless of the possibility of renegotiation.

The case in which renegotiation is not possible

Consider the case in which parties renegotiation is not possible. The following proposition shows that the optimal SC damages are under-compensatory.

Proposition 5. Assume that $T$ has some negotiation power, and that renegotiation is not possible. The SC rule cannot implement the first-best outcome, and the SC damages are generally under-compensatory (i.e., for all $\alpha \in(0,1], W^{S}<W^{*}$, and $\left.x^{S} \leq v\right)$. Proof. See the Appendix B.

When $0<\alpha<1$, the second-best damages must be strictly under-compensatory to mitigate the incentive to overinvest. When $\alpha=1, S$ 's investment is independent of the damages, and therefore, the second-best damages must be compensatory damages to guarantee efficient trading decisions. ${ }^{31}$

In a model in which $B$ invests and $S$ breaches and in which renegotiation is not possible, Chung (1992) shows that the efficient expectation damages can implement the first-best outcome even when $T$ has some negotiation power. ${ }^{32}$ In the model of this 
article, the efficient expectation damages are the same as the simple expectation damages (that is, the ED rule) because the breached-against party does not invest. Contrary to Chung (1992), in this article, the first-best outcome cannot be implemented by the efficient expectation damages because the seller's investment can be used as a commitment device against the third party independent of damages.

The case in which renegotiation is possible

Consider the case in which ex post renegotiation is possible. Since the contracting parties can renegotiate under complete information, the trading (breach) decision will be ex post efficient. Regardless of the level of the SC damages $x^{S}, T$ will get the seller's performance if $\theta>v+\Delta(e)$. Realizing the possibility of renegotiation, the third party will make a bid as if the effective damages are $v$, not $x^{S}$. As shown in (11) in the previous section, the equilibrium price bid is determined by $z=(1-\alpha) \theta+\alpha(v+\Delta(e))$

With renegotiation, the SC damages do not have any effect on the third party's bidding behavior. Because the SC damages can influence $S$ 's investment decision, however, the court can choose the SC damages $x^{S}$ such that $S$ 's investment maximizes the social welfare function. The following proposition shows that the optimal SC damages are under-compensatory again to mitigate the overinvestment.

Proposition 6. Assume that $T$ 's negotiation power is positive, but less than 1 , and that renegotiation is possible. The SC rule cannot implement the first-best outcome, and the SC damages are under-compensatory (i.e., for all $\alpha \in(0,1), W^{S}<W^{*}$, and $x^{S}<v$ ). Proof. See the Appendix B.

When $0<\alpha<1$, the SC damages must be strictly under-compensatory to mitigate the incentive to overinvest identified above. When $\alpha=1, S^{\prime}$ ' investment is independent 
of the damages. When $\alpha=1$, thus, the second-best damages are indeterminate. For the ex post renegotiation guarantees ex post efficient trading decisions.

In a model in which $B$ invests and $S$ breaches and in which renegotiation is possible, Spier and Whinston (1993) shows that the efficient expectation damages can implement the first-best outcome even when $T$ has some negotiation power. In the model of this article, however, the efficient expectation damages cannot implement the first-best outcome because the seller's investment can be used as a commitment device against the third party independent of damages.

\section{Concluding remarks}

I have investigated the incentives that parties to a contract have in making specific investments when they might interact with a third party in the future. To extract the third party's rent from the future bargain, the contracting parties have an incentive to increase the switching cost which the breaching party incurs, which in turn the third party should compensate him for in order to induce a breach. Overinvestment in assets that are specific to the contracting parties effectively raises the switching cost. It is shown in this article that, to obtain the commitment power, the breaching party overinvests under a variety of contract remedies including the standard compensatory damages.

That specific investments can be used as a commitment device has a number of implications for contract remedies. First, contrary to the existing result, the expectation damage measure does not implement the first-best outcome: it induces the breaching party to overinvest on specific assets to commit against third parties. Second, the overinvestment result is robust even when the contracting parties can renegotiate stipulated damages and when the court imposes the penalty doctrine. In particular, once specific investment is available as a commitment device, parties to a contract do not 
need to use stipulated damages. Third, the second-best optimal damages must be under-compensatory to mitigate the overinvestment problem.

As it has already been mentioned, the case in which a new seller, instead of a new buyer, comes up with a realization of her cost and makes an offer to the buyer can be symmetrically analyzed with only changes in notation. There are several works studying this case in industrial organization literature, in particular, entry deterrence models. ${ }^{33}$ An incumbent seller serves for a buyer, and may take an action (investment) to deter the entry of a competing seller. The investment that lowers the incumbent seller's marginal cost (or that raises the entrant's marginal cost) can have a commitment value against its rival because it changes the nature of duopoly equilibrium in favor of the incumbent. The incumbent can prevent its monopoly profit from being eroded by its rival's entry.

The implication of this article for the case is quite different. The results of this article suggest that the buyer, not the incumbent seller, takes a strategic action (by overinvesting on a specific asset) against its potential future partner to extract rent from the bargain. The new seller must incur some entry cost. A major part of the entry cost is the compensation that she must pay for a loss to the contracting parties due to breach. The specific investment by the buyer raises the amount of compensation that the new seller has to pay the buyer in order to induce a breach.

The specific investment can be thought of as a choice of technology. The transaction-cost economics literature maintains that an absence of a long-term contract and the resulting ex post bargaining about the terms of trade induces the parties not to specialize their investment enough, for they preserve their outside opportunities by picking general purpose technologies. In general, the party who can improve returns in some future trading relationship by specializing investment will under-specialize because they will have to share the future returns through bargaining. 
The overinvestment result in this article amounts to selecting a specialized technology (instead of selecting a general purpose technology), which directly contrasts with the prediction by the transaction cost economics literature. As hinted in the Introduction, two results are not inconsistent. The overinvestment result of this article can be understood in the following way. In the present model, the future trading relationship is between the contracting parties on one side, and the third party on the other side. When the third party has some negotiation power, he will receive parts of the returns from the bargaining with the contracting parties. If a general purpose technology is chosen, the third party will improve her bargaining position relative to the seller. The contracting parties have an incentive to specialize their investment to reduce the third party's rent.

In the present model, the seller faces an outside opportunity before he completes the original contract. The model can be interpreted as a two-period model. In the first period, the seller performs for the incumbent buyer and makes a specific investment that will reduce his second period costs. In the beginning of the second period, the seller faces a possible outside opportunity and has to decide which buyer to serve. The investment is not of much use to the new buyer. The overinvestment result of this article can be directly carried over to this situation as long as the parties can write a long-term contract that is effective for the second period. The long-term contract is incomplete in the sense that the parties to the contract cannot write a separate contract for the new buyer.

There are two other cases in which (i) long-term contracts are not feasible, and (ii) complete long-term contracts can be written for the new buyer. In the first case, in which the parties are not able to commit to a long-term contract, the incentive for investment depends on how the second period price is determined in the model. The seller may bargain with two buyers, or the two buyers may compete for the seller's service. If the seller, the investing party, receives full surplus from the bargaining, he 
will invest efficiently. If the seller shares some of the returns from investment, he will, in general, underinvest in fear of opportunism. In the present model, the parties can commit to an (incomplete) long-term contract so that the seller overinvests to improve his bargaining position vis-a-vis outside parties.

In the second case, in which complete long-term contracts can be written for the new buyer, the seller likely invests at the efficient level. Laffont and Tirole (1988) consider a second sourcing model in which a buyer designs contracts for both sellers as well as a break-out rule. In a complete information version of their model, the buyer would invest efficiently because he extracts all the surpluses from both sellers. In the present article, the parties to a contract can write only an incomplete contract, in that a contract for third parties is not feasible. The third party must bargain with the seller to determine terms of trade. The seller has an incentive to overinvest to improve his bargaining position in the bargain.

In the present model, the parties bargain under complete information, and achieve ex post efficient trades. If each party has private information about his or her willingness to trade, bargaining is bound be inefficient. ${ }^{34}$ The two parties may refrain from trade in situations where there is a surplus to be divided. In particular, the seller may fail to breach the original contract when breach is efficient. I conjecture that, in those cases, he would invest more on specific assets, because there is smaller chance of performing for the third party. It would strengthen the overinvestment result of this article. A detailed analysis of such a case with incomplete information is an interesting future research topic. 


\section{APPENDIX A.}

In Appendix A, a version of the model is analyzed by adopting a non-cooperative bargaining process as in Rubinstein (1982). First, consider the situation in which two players set out to divide a cake of a fixed size between them. Suppose that there are (infinite) bargaining periods $\{0,1,2, \ldots\}$ between Date 1 and Date 2 . The ex post bargaining process involves the parties taking turns to make proposals: at period 0 , player I (say, the seller, $S$ ) proposes that he receive some share, $s$. Player II (say, the third party, T) immediately replies "Yes" or "No". If he says "Yes", the game ends; otherwise, at next period, Player II makes a proposal to which Player I immediately replies; and so on. Assume that both players have a common discount factor $\delta$. To eliminate the first-mover advantage, let the time delay between successive periods be denoted as $\tau$, and write the discount factor as $\delta^{\tau}$ accordingly. It is shown in Sutton (1986) that, in the limit as $\tau \rightarrow 0$, the equilibrium share of Player I becomes $1 / 2$.

In the present model, the size of the cake is endogenously determined. Given investment $e$ and a realization of $T$ 's valuation $\theta$, the total bargaining surplus between $S$ and $T$ is $\theta-\tau(e)$. If they fail to agree, the seller receives $(p-x-e)$, whereas the third party receives zero. Therefore, the seller's equilibrium payoff from the bargaining would be $(p-x-e)+1 / 2[\theta-\tau(e)]$.

A notable feature of the present model is that the seller has an outside option in the bargaining with the third party, that is, the option of trading with the original buyer. The value for the seller of the outside option is $p-c(e)-e$. According to the Outside Option principle (Binmore (1987), Shaked and Sutton (1984)), the seller's equilibrium payoff is $\min \{(p-x-e)+1 / 2[\theta-c(e)],(p-c(e)-e)\}$. The third party's equilibrium payoff is either $1 / 2[\theta-c(e)]$ if the outside option is not binding, or $[\theta-(x+\Delta(e))]$ if the outside option is binding. The outside option is binding if and only if $\theta \geq(x+\Delta(e))$, and $\theta \leq(x$ $+\Delta(e))+(x-c(e))$. 
Assume that $x=v$. This can be obtained either when the court uses the ED rule (Proposition 2), or when the parties stipulate them in the contract as optimal damages (Proposition 6). This assumption is made to facilitate the comparison between the equilibrium investment and the efficient investment. When $x=v$, the value of $(x-c(e))$ is positive, because by assumption there are gains from trade in the original contract. When $(v+\Delta(e)) \leq \theta \leq(v+\Delta(e))+(v-c(e))$, thus, the seller's outside option is binding. For an expositional clarity, focus on the case in which the seller's investment is completely specific. Formally, assume that $c(e)$ is independent of $e$.

There are three possibilities depending upon the value of $\theta$. If $\theta<(v+\Delta(e))$, then there is no surplus from the bargain between $S$ and $T$. The seller will complete the original contract with $B$, and $S$ 's payoff is $(p-c(e)-e)$. If $(v+\Delta(e)) \leq \theta \leq(v+\Delta(e))$ $+(\nu-c(e))$, then the seller breaches the original contract to perform for the third party. Because her outside option is binding, $S$ 's equilibrium payoff is $(p-c(e)-e)$. Finally, if $(v+\Delta(e))+(v-c(e))<\theta$, then the seller breaches the original contract to perform for the third party. As her outside option is not binding in this case, $S$ 's equilibrium payoff is $(p-v-e)+1 / 2[\theta-c(e)]$. The seller's optimal investment is chosen to maximize her expected payoff that can be written as:

(A1)

$$
\begin{aligned}
U S(e, p) & =\int_{\{\theta \leq v+\Delta(e)+v-c(e)\}}[p-c(e)] d F(\theta) \\
& +\int_{\{\theta>v+\Delta(e)+v-c(e)\}}[(p-v)+1 / 2(\theta-c)] d F(\theta)-e .
\end{aligned}
$$

The first-best efficient investment is defined as a maximizer of the social welfare function (see Definition 1):

$$
\begin{aligned}
\tilde{W}(e) & =\int_{\{\theta \leq \nu+\Delta(e)\}}[v-c(e)] d F(\theta) \\
& +\int_{\{\theta>v+\Delta(e)\}}[\theta-c] d F(\theta)-e
\end{aligned}
$$


The comparison of these two formulae reveals that there is an incentive for overinvestment in equilibrium. When $(v+\Delta(e)) \leq \theta \leq(v+\Delta(e))+(v-c(e))$, the seller's outside option is binding, and $S$ 's equilibrium payoff is $(p-c(e)-e)$. The seller perceives that her investment is valuable in reducing the cost $c(e)$. From the social perspective, however, the specific investment does not have any value because the seller breaches the original contract and now serves for the third party. Overinvestment in specific assets improves the seller's bargaining position vis-a-vis the third party because it raises the value of the seller's outside option. The investment also increases the probability of the event that the outside option is binding. In summary, this confirms that the main insight of this article is not sensitive to a particular bargaining process.

\section{APPENDIX B.}

Appendix B contains proofs of Propositions 3, 4, 5, and 6.

Lemma 1. Assume that renegotiation is not possible. Then, $e(x, \alpha)$ is increasing in $x$ and $\alpha$.

Proof. Recall that the seller's optimal investment decision $e(x, \alpha)$ is characterized by

$$
U S_{e}(e, \mathrm{x} ; \alpha) \equiv-c^{\prime}(e)-1-(1-\alpha)[1-F(x+\Delta(e))] \Delta^{\prime}(e)=0 .
$$

By the implicit function theorem, $\frac{\partial e(x, \alpha)}{\partial x}=-\frac{(1-\alpha) f(x+\Delta(e)) \Delta^{\prime}(e)}{U_{e e}^{S_{e e}}} \geq 0$ because $\Delta^{\prime}>0$ and $U_{e e}^{S}<0$ from the second-order condition. ${ }^{35}$ Similarly, $\frac{\partial e(x, \alpha)}{\partial \alpha}=-\frac{[1-F(x+\Delta(e))] \Delta^{\prime}(e)}{U^{S} e_{e}} \geq 0$. Q.E.D. 
When the contracting parties are better protected from a possible breach of contract by larger damages, the seller has an incentive to invest more. Similarly, when $T$ 's share is greater (that is, bigger $\alpha$ ), $S$ loses more of the expected gains from switching. To reduce the expected gains from switching, thus, $S$ has an incentive to invest more on specific assets.

Proof of Proposition 3: Fix $\alpha>0$.

First, show that $x^{F}>v$. By definition, $x^{F}$ is chosen to maximize the contracting parties' joint payoff $U^{B+S}(e, x) \equiv v-c(e)-e+[1-F(x+\Delta(e))][x-v]+(1-\alpha) \int_{\Omega}[\theta-(x$ $+\Delta(e))] d F(\theta) \quad$ given that the seller's investment decision is $e(x, \alpha)$. After substituting $e(x, \alpha)$ for $e$, the first-order condition for $x^{\mathrm{F}}$ is

$$
\begin{aligned}
\frac{d U^{B+S}}{d x} & =\frac{\partial U^{B+S}}{\partial x}+\frac{\partial e(x, \alpha)}{\partial x} \frac{\partial U^{B+S}}{\partial e} \\
= & \alpha[1-F(x+\Delta(e))]-f(x+\Delta(e))[x-v]-\frac{\partial e(x, \alpha)}{\partial x} f(x+\Delta(e))[x-v] \Delta^{\prime}(e)=0 \\
& =\alpha[1-F(x+\Delta(e))]-\left(1+\frac{\partial e(x, \alpha)}{\partial x} \Delta^{\prime}\right) f(x+\Delta(e))[x-v]=0
\end{aligned}
$$

Since $\left.\frac{d U^{B+S}}{d x}\right|_{x=v}=\alpha[1-F(v+\Delta(e))]>0$, we obtain $x^{\mathrm{F}}>v$. Because $e(x, \alpha)$ is increasing in both $x$ and $\alpha$ from Lemma 1, we obtain $e\left(x^{\mathrm{F}}, \alpha\right)>e(v, \alpha)>e(v, 0)=e^{*}$.

Next, consider the outcome under the penalty doctrine. Under the penalty doctrine, the actual damages the court awards are the minimum between the stipulated damages $x^{F}$ and compensatory damages $v$. It has been shown that $x^{F}$ exceeds $v$. Therefore, the actual damages the court awards are compensatory damages $v$. Because the damages are the same as those under the ED rule, equilibrium outcomes will be the same under either rule. In particular, under the penalty doctrine, $S$ has an incentive to overinvest. Q.E.D. 
Lemma 2. Assume that renegotiation is possible. Then, $e(x, \alpha)$ is increasing in $x$. Proof.

[Step 1] Assume that the court selects SC damages $x$. Consider the case in which renegotiation is possible. Because the renegotiation is conducted under complete information, the contracting parties will choose efficient breach decisions. As the contracting parties together face a consume-or-sell decision of the seller's contractual capacity, they will let the third party receive the seller's performance if and only if their joint surplus from accepting a price bid, $z-c(e)$, is greater than or equal to the internal value of the seller's capacity, $v-c(e)$, or equivalently if $z \geq v+\Delta(e)$. Understanding this logic, the third party with negotiation power $\alpha$ will make a bid as:

$$
z(\theta, x, e, \alpha)=(1-\alpha) \theta+\alpha(v+\Delta(e))
$$

The SC damages have no effect on the third party's bidding behavior. Because the SC damages can influence $S$ 's investment decision, however, the court can choose the SC damages $x^{S}$ such that $S$ 's investment maximizes the social welfare function $W(e, x)$.

[Step 2] Next, consider $S$ 's breach decision. Given $p, x$, and $e$, without renegotiation, $S$ will accept a bid $z$ if $p+z-x-\varepsilon(e)-e \geq p-c(e)-e$, or equivalently $z \geq$ $x+\Delta(e)$. Without a further renegotiation, $S$ will breach the contract to perform for $T$ if and only if $\theta \geq \hat{\theta}(x) \equiv x+\Delta(e)+\frac{\alpha}{1-\alpha}(x-v)$ from (A3). To obtain $S^{\prime}$ s expected payoff, examine the following two cases separately depending on the relative size of $x$ and $v$. 
[Case 1: when $v \leq x$ ]

If $\theta<\hat{\theta}(v), S$ does not want to breach, which is optimal to the contracting parties, and $S^{\prime}$ s ex post payoff is $[p-c(e)]$. If $\hat{\theta}(x) \leq \theta, S$ wants to breach, which is also jointly optimal. Thus, $S$ 's ex post payoff is $[p+z-\tau(e)-x]=[p-c(e)+z-\Delta(e)-x]=[p-c(e)$ $+(1-\alpha)\{\theta-(v+\Delta(e))\}-(x-v)]$.

If $\hat{\theta}(v) \leq \theta<\hat{\theta}(x)$, breach is jointly optimal, but $S$ does not want to breach because $z<x+\Delta(e)$. The generalized Nash Bargaining solution is used to determine each party's share from the renegotiation. The buyer receives a share $\beta \in[0,1]$ of the additional surplus generated as a result of renegotiation, and the seller receives a share $(1-\beta) . S^{\prime} \mathrm{s}$ ex post payoff is $[p-c(e)+(1-\beta)(1-\alpha)\{\theta-(\nu+\Delta(e))\}]$. By combining all three cases, $S$ 's expected payoff can be written as:

(A4)

$$
\begin{aligned}
& U S(e, x)=\int_{\{\theta<\hat{\theta}(v)\}}[p-c(e)] d F(\theta) \\
& +\int_{\{\hat{\theta}(x) \leq \theta\}}[p-c(e)+(1-\alpha)\{\theta-(v+\Delta(e))\}-(x-v)] d F(\theta) \\
& +\int_{\{\hat{\theta}(v) \leq \theta<\hat{\theta}(x)\}}[p-c(e)+(1-\beta)(1-\alpha)\{\theta-(v+\Delta(e))\}] d F(\theta) \\
& -e \\
& =p-c(e)-e+(1-\alpha) \int_{\left\{\theta \geq \hat{\theta}_{(v)\}}[\theta-(v+\Delta(e))] d F(\theta)\right.} \\
& -\beta(1-\alpha) \int_{\{\hat{\theta}(v) \leq \theta \leq \hat{\theta}(x)\}}[\theta-(v+\Delta(e))] d F(\theta) \\
& -(x-v)[1-F(\hat{\theta}(x))] .
\end{aligned}
$$

The seller's optimal investment decision $e(x, \alpha)$ is characterized by

$$
\begin{aligned}
U_{e}^{S}(e, x ; \alpha) \equiv-c^{\prime}(e)-1-(1-\alpha)[1-F(\hat{\theta}(v))] \Delta^{\prime}(e) \\
+\beta(1-\alpha)\left[F(\hat{\theta}(x)-F(\hat{\theta}(v))] \Delta^{\prime}(e)=0\right.
\end{aligned}
$$


By the implicit function theorem,

$$
\frac{\partial e(x, \alpha)}{\partial x}=-\frac{\beta(1-\alpha) f(\hat{\theta}(x)) \Delta^{\prime}(e)}{U_{e e}^{S}}>0 \text { for } x \geq v
$$

because $\Delta^{\prime}>0$ and $U_{e e}^{S}<0$ from the second-order condition.

[Case 2: when $x<v$ ]

If $\theta<\hat{\theta}(x), S$ does not want to breach, which is optimal to the contracting parties, and $S^{\prime} \mathrm{s} e x$ post payoff is $[p-c(e)]$. If $\hat{\theta}(v) \leq \theta, S$ wants to breach, which is also jointly optimal. Thus, $S$ 's ex post payoff is $[p+z-c(e)-x]=[p-c(e)+z-\Delta(e)-x]=[p-c(e)$ $+(1-\alpha)\{\theta-(v+\Delta(e))\}-(x-v)]$.

If $\hat{\theta}(x) \leq \theta<\hat{\theta}(v), S$ wants to breach, which is not optimal to the contracting parties. After renegotiation, $S^{\prime} \mathrm{s}$ ex post payoff is $[p-c(e)+(1-\alpha)\{\theta-(v+\Delta(e))\}-$ $(x-v)+(1-\beta)(1-\alpha)\{\theta-(v+\Delta(e))\}]$. By combining all three cases, $S$ 's expected payoff can be written as:

$$
\text { (A6) } \begin{aligned}
U S(e, x)= & \int_{\{\theta<\hat{\theta}(x)\}}[p-c(e)] d F(\theta) \\
& +\int_{\{\hat{\theta}(v) \leq \theta\}}[p-c(e)+(1-\alpha)\{\theta-(v+\Delta(e))\}-(x-v)] d F(\theta) \\
& +\int_{\{\hat{\theta}(x) \leq \theta<\hat{\theta}(v)\}}[p-c(e)+(1-\alpha)\{\theta-(v+\Delta(e))\}-(x-v) \\
& +(1-\beta)(1-\alpha)\{\theta-(v+\Delta(e))\}] d F(\theta)-e \\
= & p-c(e)-e+(1-\alpha) \int_{\{\hat{\theta}(v) \leq \theta\}}[\theta-(v+\Delta(e))] d F(\theta) \\
& +(1-\alpha)(2-\beta) \int_{\{\hat{\theta}(x) \leq \theta<\hat{\theta}(v)\}}[\theta-(v+\Delta(e))] d F(\theta) \\
& -(x-v)[1-F(\hat{\theta}(x))] .
\end{aligned}
$$


The seller's optimal investment decision $e(x, \alpha)$ is characterized by

$$
\begin{aligned}
U_{e}^{S}(e, x ; \alpha) \equiv-c^{\prime}(e)-1- & (1-\alpha)[1-F(\hat{\theta}(v))] \Delta^{\prime}(e) \\
& -(1-\alpha)(2-\hat{\beta})\left[F(\hat{\theta}(v)-F(\hat{\theta}(x))] \Delta^{\prime}(e)=0\right.
\end{aligned}
$$

By the implicit function theorem,

(A7)

$$
\frac{\partial e(x, \alpha)}{\partial x}=-\frac{(1-\alpha)(2-\beta) f(\hat{\theta}(x)) \Delta^{\prime}(e)}{U_{e e}^{S}}>0 \text { for } x<v
$$

because $\Delta^{\prime}>0$ and $U_{e e}^{S}<0$ from the second-order condition.

[Step 3] Lemma 2 can be directly obtained from (A5) and (A7). Q.E.D.

Proof of Proposition 4. Consider the case in which the parties to a contract can stipulate, in the initial contract, damages and renegotiate them ex post. Because the renegotiation is conducted under complete information, the contracting parties will choose efficient breach decisions. As the contracting parties together face a consumeor-sell decision of the seller's contractual capacity, they will let the third party receive the seller's performance if and only if their joint surplus from accepting a price bid, $z-c$ $(e)$, is greater than or equal to the internal value of the seller's capacity, $v-c(e)$, or equivalently if $z \geq v+\Delta(e)$. Understanding this logic, the third party with negotiation power $\alpha$ will make a bid as (See (A3)):

$$
z(\theta, x, e, \alpha)=(1-\alpha) \theta+\alpha(v+\Delta(e))
$$


The joint expected payoff to the contracting parties is

$$
\begin{aligned}
U^{B+S}(e ; x)= & \int_{\{\theta<v+\Delta(e)\}}[v-c(e)] d F(\theta)+\int_{\{\theta \geq v+\Delta(e)\}}[z-\tau(e)] d F(\theta)-e \\
& =v-c(e)-e+(1-\alpha) \int_{\{\theta \geq v+\Delta(e)\}}[\theta-(v+\Delta(e))] d F(\theta)
\end{aligned}
$$

Stipulated damages have no effect on their joint payoffs as well as on the third party's bidding behavior. Because stipulated damages can influence $S$ 's investment decision, however, the contracting parties want to choose stipulated damages $x$ such that $S^{\prime}$ 's investment maximizes their joint payoffs $U^{B+S}(e)$.

Consider $S$ 's investment decision. It is shown in the proof of Lemma 2 that when $v \leq x, S$ 's expected payoff is expressed by

$$
\begin{aligned}
U^{S}(e, x) & =p-c(e)-e+(1-\alpha) \int_{\{\theta \geq \hat{\theta}(v)\}}[\theta-(v+\Delta(e))] d F(\theta) \\
& -\beta(1-\alpha) \int_{\{\hat{\theta}(v) \leq \theta \leq \hat{\theta}(x)\}}[\theta-(v+\Delta(e))] d F(\theta) \\
& -(x-v)[1-F(\hat{\theta}(x))] .
\end{aligned}
$$

From (A4), when $x=v, U^{B+S}(e)=U^{S}(e ; x)+(v-p)$ because the last two terms in (A4) vanish. When stipulated damages are equal to compensatory damages (that is, equal to expectation damages), $S$ has an incentive to choose an investment to maximize their joint expected payoff, which is exactly what the contracting parties want to do in selecting stipulated damages. On the other hand, if stipulated damages exceed compensatory damages (i.e., when $\hat{\theta}(v) \leq \theta<\hat{\theta}(x)$ ), there will be a need for renegotiation. Accordingly, the gains from the renegotiation must be shared between $B$ and $S$. The parties do not want to set such high stipulated damages because it will distort $S$ 's investment decision which will reduce their joint expected payoff. 
It is shown in the proof of Lemma 2 that when $x<v, S^{\prime}$ s expected payoff is expressed by

$$
\begin{aligned}
& U^{S}(e, x)=p-c(e)-e+(1-\alpha) \int_{\{\hat{\theta}(v) \leq \theta\}}[\theta-(v+\Delta(e))] d F(\theta) \\
& +(1-\alpha)(2-\beta) \int_{\{\hat{\theta}(x) \leq \theta<\hat{\theta}(v)\}}[\theta-(v+\Delta(e))] d F(\theta) \\
& -(x-v)[1-F(\hat{\theta}(x))] .
\end{aligned}
$$

Observe that when $x=v, U^{B+S}(e)=U^{S}(e ; x)+(v-p)$ because the last two terms in (A6) vanish. When stipulated damages are equal to compensatory damages (that is, equal to expectation damages), $S$ has an incentive to choose such an investment to maximize their joint expected payoff, which is exactly what the parties want to do in selecting stipulated damages. If stipulated damages are smaller than compensatory damages (that is, when $\hat{\theta}(x) \leq \theta<\hat{\theta}(v)$ ), there will be a need for renegotiation. Accordingly, the gains from the renegotiation must be shared between $B$ and $S$. The parties do not want to set such low stipulated damages because it will distort $S^{\prime}$ s investment decision which will reduce the joint expected payoff.

In summary, when the contracting parties can stipulate damages and are able to renegotiate ex post, the optimal stipulated damages are at the same level as the expectation damages. Therefore, the equilibrium outcome is exactly the same as the one under the $E D$ rule. Q.E.D.

Proof of Proposition 5. The social planner determines the SC damages $x^{S}$ by maximizing the social welfare function $W(e, x)$ after taking the seller's investment decision into consideration. 


$$
\begin{aligned}
& x^{S} \quad \text { maximizes } W(e, x)=v-c(e)-e+[1-F(x+\Delta(e))][x-v] \\
& +\int_{\Omega}[\theta-(x+\Delta(e))] d F(\theta) \\
& \text { subject to } e=e(x, \alpha)=\operatorname{argmax}_{\{e\}} U^{S}(e, x ; \alpha)
\end{aligned}
$$

The first-order condition for $x^{s}$ is given by

$$
\begin{aligned}
0=\frac{\mathrm{d} W}{\mathrm{~d} x} & =\frac{\partial W}{\partial x}+\frac{\partial W}{\partial e} \frac{\partial e(x, \alpha)}{\partial x} \\
= & -f(x+\Delta(e))[x-v]+\frac{\partial W}{\partial e} \frac{\partial e(x, \alpha)}{\partial x} \\
= & -f(x+\Delta(e))[x-v] \\
& +\left\{U_{e}-f(x+\Delta(e))[x-v] \Delta^{\prime}(e)-\alpha[1-F(x+\Delta(e))] \Delta^{\prime}(e)\right\} \frac{\partial e(x, \alpha)}{\partial x} \text { from (10). } \\
= & -f(x+\Delta(e))[x-v] \\
& -\left\{f(x+\Delta(e))[x-v] \Delta^{\prime}(e)+\alpha[1-F(x+\Delta(e))] \Delta^{\prime}(e)\right\} \frac{\partial e(x, \alpha)}{\partial x}
\end{aligned}
$$

because $U S_{e}=0$ from $S$ 's optimization.

$$
\text { When } \alpha=1, \frac{\partial e(x, \alpha)}{\partial x}=0 \text {, and thus }\left.\frac{\mathrm{d} W}{\mathrm{~d} x}\right|_{x=\nu}=0 \text {. Hence, } x^{S=v} \text { (just- }
$$

compensatory). It does not implement the first-best outcomes, however, because the resulting investment $e_{e}$ is greater than the first-best level $e^{*}$.

Fix $\alpha \in(0,1)$. Note that $\left.\frac{\mathrm{d} W}{\mathrm{~d} x}\right|_{x=v}=-\alpha[1-F(v+\Delta(e(v, \alpha)))] \Delta^{\prime}(e) \frac{\partial e(x)}{\partial x}<0$ from Lemma 1. Because the social welfare function is decreasing in $x$ at $v$, the SC damages $x^{S}$ must be less than $v$. This proves that the SC damages are under-compensatory, which induces inefficient breach decisions. Q.E.D. 
Proof of Proposition 6. The social planner determines the SC damages $x^{S}$ by maximizing the social welfare function $W(e, x)$ after taking the seller's investment decision into consideration as shown in the proof of Proposition 3.

$$
\begin{array}{r}
x^{S} \quad \begin{array}{r}
\text { maximizes } W(e, x)=v-c(e)-e+[1-F(x+\Delta(e))][x-v] \\
+\int_{\Omega}[\theta-(x+\Delta(e))] d F(\theta)
\end{array} \\
\text { subject to } e=e(x, \alpha)=\operatorname{argmax}_{\{e\}} U S(e, x ; \alpha)
\end{array}
$$

The first-order condition for $x^{S}$ is given by

$$
\begin{aligned}
0=\frac{\mathrm{d} W}{\mathrm{~d} x} & =-f(x+\Delta(e))[x-v] \\
& -\left\{f(x+\Delta(e))[x-v] \Delta^{\prime}(e)+\alpha[1-F(x+\Delta(e))] \Delta^{\prime}(e)\right\} \frac{\partial e(x, \alpha)}{\partial x} .
\end{aligned}
$$

Fix $\alpha \in(0,1)$. Note that $\left.\frac{\mathrm{d} W}{\mathrm{~d} x}\right|_{x=v}=-\alpha[1-F(v+\Delta(e))] \Delta^{\prime}(e) \frac{\partial e(x)}{\partial x}<0$ from Lemma 2. Because the social welfare function is decreasing in $x$ at $v$, the SC damages $x$ must be less than $v$. This proves that the SC damages are under-compensatory, which mitigates overinvestment at the expense of inefficient breach decisions. Q.E.D. 


\section{FOOTNOTES}

1 The same point has been made in Chung (1992).

2 The same point has been made in Dixit and Nalebuff (1991, pp 149-151) and Spier and Whinston (1993).

3 The seller has outside opportunities before the contract is completed. For instance, a defense contractor could elect to supply foreign governments rather than the home ministry of defense or to focus on civilian activities. In employment relationships, a worker may take a new job before her existing employment contract expires. The worker may have to incur a mobility cost or the cost of retraining if she has made relationship-specific investments on the old job.

4 In this article, switching costs are endogenous. If the switching cost were exogenous, there would be no incentive for overinvestment. For models with exogenous switching cost, see Farell and Shapiro (1988), and Klemperer $(1987,1992)$.

5 See Williamson (1985), Klein, Crawford, and Alchian (1978), and Grossman and Hart (1986).

6 A similar overinvestment result, but arising due to changes in asset ownership, is obtained in a recent work by Bolton and Whinston (1993).

7 The expectation damages measure awards the victim of breach an amount of money that fully compensates him as if the contract had been performed.

8 The case in which the breaching party invests has been neglected in the literature ever since Shavell (1980), perhaps because Shavell showed that the first-best outcome can be obtained under the standard compensatory damages when the third party does not have any negotiation power.

9 Provided that the default contract remedy is standard compensatory damages, it is shown that parties to a contract do not have an incentive to stipulate other damages if penalty doctrine is adopted or if renegotiation is possible. See Section 5. 
10 The efficient expectation damages differ from expectation damages only when the victim of breach invests. The efficient expectation damages are defined as the expectation damages that would result if the victim made the efficient investment.

11 See Shavell (1980).

12 The seller engages in expenditures on specific asset before the contractual performance to prepare to perform it. In legal terminology, such an investment is called reliance because the seller is investing in relying upon the contract.

13 The situation is that the promisor can use the resources committed to the performance of the contract to produce something different and more valuable than that promised to the original promisee. An example of this situation in the legal literature is Lumley v. Gye (1853), in which a competing producer enticed an opera singer under contract to the plaintiff to sing instead for the competitor.

14 An example would be the entry deterrence model in which an incumbent seller may compete with a new seller to serve a buyer. Another case is the second sourcing model in which a buyer may replace an incumbent supplier by a second supplier. The present model precludes any contractual relationship between the buyer and the second supplier. For a further discussion, see Section 6.

15 If investment were general, then $\Delta^{\prime}(e)=0$.

16 In other words, $e_{e}$ is the level of $S$ 's optimal investment when the probability of switching is zero.

17 In other words, they are sufficiently complex that it would be prohibitively costly to describe them in such a way that an outside court could verify them. If $\theta$ were contractible, then the contracting parties would be able to use a perfect price discrimination to fully capture all the rents. In that case, overinvestment cannot be obtained. 
18 Even if $e$ were contractible, the main result of this article - overinvestment effect would not be changed. This is true because the contracting parties, not just the seller, have an incentive to extract more rents from the third party by raising the switching cost.

19 The damage payment is paid from the breaching party $S$ to the breached-against party $B$. The third party $T$ and $S$ could agree that $T$ will indemnify $S$ if $S$ is called upon to pay the damages. The results of this paper are not changed under this alternative specification.

20 For the importance of observability in commitment models, see Bagwell (1992).

21 In Appendix A, a version of the model is examined by adopting a non-cooperative bargaining process as in Rubinstein (1982), and the similar overinvestment result is obtained by using the outside option principle.

22 This is the specification used in Shavell (1980).

23 The contract price $p$ is presumably determined by the relative negotiation power between $B$ and $S$. Note that $p$ must satisfy voluntary participation constraints for both contracting parties at the time of singing a contract. For example, suppose that B designs a contract and makes a take-it-or-leave-it offer to $S$. $S$ 's reservation payoff can be obtained endogenously by calculating his expected payoff when he does not accept any contract, and when he waits until $\theta$ is realized and bargain with either $B$ or $T$.

24 An amount of damages that are greater than compensatory damages is called overcompensatory. Similarly, an amount of damages that are smaller than compensatory damages is called under-compensatory.

25 See also Shavell (1980, p. 485, Proposition 8) for another proof.

26 The overinvestment also depends on the contracting parties' belief on the distribution of $T$ 's valuation, $F(\theta)$. If the parties' belief puts more weight on higher valuations, the incentive for overinvestment becomes stronger. Formally, if $F_{1}(\theta)>$ $F_{2}(\theta)$ for all $\theta$ (first-order stochastic dominance), then $e\left(F_{1}\right)<e\left(F_{2}\right)$, ceteris paribus. 
27 There is one caveat of the SC damages: to correctly calculate the damages, the court must know the social welfare function. The informational requirement can be quite demanding.

28 Suppose that $B$ makes (reliance) investment $r$. Now, $B$ 's gross utility is $v(r)$ which is an increasing function. The efficient expectation damages are defined by $v\left(r^{*}\right)$, where $r^{*}$ is the first-best level of $r$.

29 A similar result has been shown in models in which none of the parties invest (Aghion and Bolton (1987)), and cases in which only the breached-against party invests (Chung (1992)).

30 The material studied in this part has been suggested by Michael Whinston.

31 Spier and Whinston (1993) study a model in which stipulated damages can be renegotiation in the case where the breached-against party invests. The revised version of their paper also incorporates a discussion of the case where the breaching party invests. See also Rogerson (1980) for a model in which renegotiation is allowed.

32 In this case, the optimal stipulated damages will be enforced even if the penalty doctrine is imposed.

33 See Dixit (1980) and Tirole (1988, Chapter 8).

34 For the inefficiency of bargaining when both parties have private information, see Myerson and Satterthwaite (1983).

35 It is assumed that each maximization program has a unique interior maximum characterized by the first-order conditions for the maximization program. 


\section{REFERENCES}

Aghion, Philippe and Bolton, Patrick, "Contracts as a Barrier to Entry," American Economic Review, June 1987, 77, 388-401.

Bagwell, Kyle, "Commitment and Observability in Games," Northwestern University Discussion Paper No. 1014, 1992.

Binmore, Ken, "Nash Bargaining Theory II," in Binmore, K. and Dasgupta, P. (Eds.), The Economics of Bargaining, Oxford: Blackwell, 1987.

Bolton, Patrick and Whinston, Michael D., "Incomplete Contracts, Vertical Integration, and Supply Assurance," Review of Economic Studies, 1993, 60, 121-148.

Chung, Tai-Yeong, "On the Social Optimality of Liquidated Damage Clauses: An Economic Analysis," Joumal of Law, Economics, \& Organization, April 1992, 8, 280-305.

Dixit, Avinash, "The Role of Investment in Entry-Deterrence," Economic Journal, March 1980, 90, 95-106. and Nalebuff, Barry, Thinking Strategically, New York, W. W. Norton \& Company, 1991.

Farell, Joseph and Shapiro, Carl, "Dynamic Competition with Switching Costs," Rand Journal of Economics, Spring 1988, 19, 123-137.

Grossman, Sanford J. and Hart, Oliver D., "Costs and Benefits of Ownership: A Theory of Vertical and Lateral Integration," Journal of Political Economy, 1986, 94, 691719.

Klein, Benjamin, Crawford, Robert G., and Alchian, Armen A., "A Vertical Integration, Appropriable Rents, and the Competitive Contracting Process," Journal of Law and Economics, 1978, 21, 297-326. 
Klemperer, Paul, "Markets with Consumer Switching Costs," Quarterly Journal of Economics, May 1987, 102, 375-394.

, "Competition When Consumers have Switching Costs: An Overview", mimeo, Oxford University, 1992.

Krattenmaker, Thomas G. and Salop, Steven C., "Anticompetitive Exclusion: Raising Rival's Costs to Achieve Power over Price," Yale Law Journal, December $1986,96,209-293$.

Laffont, Jean-Jacques and Tirole, Jean, "Repeated Auctions of Incentive Contracts, Investment, and Bidding Parity with an Application to Takeovers", Rand Journal of Economics, 1988, 19, 516-537.

Masten, Scott E. and Snyder, Edward A., "The Design and Duration of Contracts: Strategic and Efficiency Considerations," Law and Contemporaray Problems, $1989,52,63-85$.

Myerson, Roger B. and Satterthwaite, Mark A., "Efficient Mechanisms for Bilateral Trading," Journal of Economic Theory, April 1983, 29, 265-281.

Rogerson, William P., "Efficient Reliance and Damage Measure for Breach of Contract", Rand Journal of Economics, 1984, 15, 39-53.

Rubinstein, Ariel, "Perfect Equilibrium in a Bargaining Model," Econometrica, 1982, 50, 97-109.

Shaked, Avner and Sutton, John, "Involuntary Unemployment as a Perfect Equilibrium in a Bargaining Model," Econometrica, 1984, 52, 1351-1364.

Schelling, Thomas C. , The Strategy of Conflict, Cambridge: Harvard University Press, 1960.

Shavell, Steven, "Damage measures for Breach of Contract," Bell Journal of Economics, Autumn 1980, 11, 466-490. 
Spier, Kathryn E. and Whinston, Michael D., "On the Efficiency of Privately Stipulated Damages for Breach of Contract: Entry Barriers, Reliance, and Renegotiation," Harvard University Discussion Paper 1649, revised, 1993.

Sutton, John, "Non-Cooperative Bargaining Theory: An Introduction," Review of Economic Studies, 1986, 53, 709-724.

Tirole, Jean, The Theory of Industrial Organization, Cambridge: MIT Press, 1988.

Williamson, Oliver, The Economic Institutions of Capitalism. New York: The Free Press, 1985.

Lumley v. Gye, 2 El. \& Bl. 216, 118 Eng. Rep. 749, 1853. 


$\begin{array}{cccc}\begin{array}{c}\text { contract is signed } \\ \text { between } B \text { and } S\end{array} & \begin{array}{c}\text { uncertainty } \theta \\ \text { is realized }\end{array} & \begin{array}{c}\text { contract is completed } \\ \text { or breached }\end{array} \\ \begin{array}{c}\text { Date } 0 \\ \leftarrow\end{array} & \begin{array}{c}\text { Date } 1 \\ \text { by } S\end{array} & \rightarrow \leftarrow & \begin{array}{c}\text { bargaining } \\ \text { between } S \text { and } T\end{array}\end{array}$

FIGURE 1 